\title{
Purple nutsedge (Cyperus rotundus L.) extract as carrot growth and production inducer
}

Geraldo Pastore ${ }^{1}$, César Antônio da Silva ${ }^{2}$, Nelson Geraldo Golinski ${ }^{1}$, Fernando Zuchello ${ }^{3}$, Cícero José da Silva ${ }^{2}$

${ }^{1}$ Instituto Federal Catarinense - IFC, Campus Concórdia, SC. ${ }^{2}$ Instituto Federal Goiano - IF Goiano, GO. ${ }^{3}$ Faculdade Concórdia - FACC, SC. E-mail: cesar.antonio@ifgoiano.edu.br

\begin{abstract}
There is evidence that the purple nutsedge (Cyperus rotundus L.) aqueous extract can induce the plants rooting due to the high auxin concentrations. This study aimed to evaluate the effect of application seasons and concentrations of purple nutsedge aqueous extract application on the growth and production of carrot, cultivar Brasília. The experimental design was in randomized blocks, in a $2 \times 5$ factorial scheme in two seasons of the extract application ( 25 and 50 days after sowing) and five concentrations of $(0 \%, 10 \%, 20 \%$, $30 \%$ and $40 \%$ ) with four replicates. Harvesting was carried out at 90 days after sowing, being evaluated the following morphological parameters: root diameter $(\mathrm{cm})$; root fresh mass $\left(\mathrm{g} \mathrm{plant}^{-1}\right)$; plant height $(\mathrm{cm})$; aerial part fresh mass ( $\left.\mathrm{g} \mathrm{plant}^{-1}\right)$; root dry mass $\left(\mathrm{g} \mathrm{plant}^{-1}\right)$; aerial part dry mass $\left(\mathrm{g} \mathrm{plant}^{-1}\right)$; plant dry mass $(\mathrm{g}$ plant $\left.{ }^{-1}\right)$; ratio between root dry mass and aerial part dry mass; root length $(\mathrm{cm})$; commercial productivity $(\mathrm{t}$ $\mathrm{ha}^{-1}$ ); defective root mass $\left(\mathrm{t} \mathrm{ha} \mathrm{H}^{-1}\right)$; total productivity $\left(\mathrm{t} \mathrm{ha}{ }^{-1}\right)$; commercial yield (roots $\mathrm{kg}^{-1}$ ); and root classification by length. The extract application at $50^{\text {th }}$ day was more efficient for the root diameter (3.37 $\mathrm{cm})$; fresh root mass $\left(120.7 \mathrm{~g} \mathrm{plant}^{-1}\right)$; root length $(15.4 \mathrm{~cm})$; commercial productivity $\left(68.2 \mathrm{t} \mathrm{ha}^{-1}\right)$; total productivity $\left(73.6 \mathrm{t} \mathrm{ha}^{-1}\right)$; and commercial roots $\left(8.8\right.$ roots $\left.\mathrm{kg}^{-1}\right)$. Root classification by length showed a higher percentage in the $14 \mathrm{~cm}$ classification range. The parameters did not present significant differences in both seasons, at $25^{\text {th }}$ and $50^{\text {th }}$ days, respectively, for root dry mass ( 12.0 and $\left.12.8 \mathrm{~g} \mathrm{plant}^{-1}\right)$, ratio between dry mass of roots and aerial part (1.66 and 1.57), and defective root mass (1.3 and $1.5 \mathrm{t} \mathrm{ha}^{-1}$ ).
\end{abstract}

Keywords: auxins; Daucus carota L.; rooting.

\section{Extrato de tiririca (Cyperus rotundus L.) como indutor de crescimento e produção de cenoura}

\section{Resumo}

Há evidências de que o extrato aquoso de tiririca (Cyperus rotundus L.) possa induzir o enraizamento de plantas, por apresentar elevadas concentrações de auxinas. O objetivo deste trabalho foi avaliar o efeito de épocas de aplicação e concentrações de extrato aquoso de tiririca no desenvolvimento e produção da cenoura, cultivar Brasília. 0 delineamento experimental foi em blocos casualizados, em esquema fatorial $2 \mathrm{x}$ 5 , sendo duas épocas de aplicação do extrato ( 25 e 50 dias após semeadura) e cinco concentrações de extrato de tiririca $(0 \%, 10 \%, 20 \%, 30 \%$ e $40 \% \mathrm{v} / \mathrm{v})$, com 4 repetições. A colheita foi realizada aos 90 dias após a semeadura, sendo avaliados os seguintes parâmetros morfológicos: diâmetro de raízes $(\mathrm{cm})$; altura de plantas $(\mathrm{cm})$; massa fresca de raízes e da parte aérea $\left(\mathrm{g} \mathrm{planta}^{-1}\right)$; massa seca de raízes e da parte aérea (g planta ${ }^{-1}$ ); massa seca total (g planta $\left.{ }^{-1}\right)$; razão das massas seca de raízes e parte aérea; comprimento de raízes $(\mathrm{cm})$; produtividade comercial $\left(\mathrm{t} \mathrm{h}^{-1}\right)$; massa de raízes com defeito $\left(\mathrm{t} \mathrm{ha}{ }^{-1}\right)$; produtividade total $\left(\mathrm{t} \mathrm{ha}^{-1}\right)$; rendimento comercial (raízes $\mathrm{kg}^{-1}$ ); e classificação das raízes por comprimento. A aplicação do extrato aos 50 dias mostrou-se mais eficiente ao diâmetro de raiz $(3,37 \mathrm{~cm})$, massa fresca de raízes $\left(120,7 \mathrm{~g}_{\text {planta }}{ }^{-1}\right)$, comprimento de raízes $(15,4 \mathrm{~cm})$, produtividade comercial $\left(68,2 \mathrm{t} \mathrm{ha}^{-1}\right)$, produtividade total $\left(73,6 \mathrm{t} \mathrm{ha}^{-1}\right) \mathrm{e}$ raízes comerciais $\left(8,8\right.$ raízes $\left.\mathrm{kg}^{-1}\right)$. A classificação das raízes apresentou maior porcentagem na classe de 14 $\mathrm{cm}$. Os parâmetros massa seca de raiz $\left(12,0\right.$ e $12,8 \mathrm{~g}$ planta $\left.^{-1}\right)$, razão de massa seca de raízes e parte aérea $(1,66$ e 1,57$)$ e massa de raízes com defeito $\left(1,3\right.$ e $\left.1,5 \mathrm{t} \mathrm{ha}^{-1}\right)$, aos 25 e 50 dias, respectivamente, foram semelhantes em ambas as épocas.

Palavras-chave: auxinas; Daucus carota L.; enraizamento. 


\section{Introdução}

A cenoura é cultivada em todo o território nacional, com destaque para os estados de Minas Gerais, Goiás, Bahia, São Paulo, Paraná e Rio Grande do Sul. A produção nacional é da ordem de 760,6 mil toneladas, numa área de 24,1 mil hectares, proporcionando produtividade média de 31,6 $\mathrm{t} \mathrm{ha}^{-1}$ (ANUÁRIO BRASILEIRO DE HORTALIÇAS, 2017). O consumo per capita de cenoura no Brasil é de, aproximadamente, $5,8 \mathrm{~kg}$ $a^{-1} o^{-}$, sendo uma das cinco hortaliças mais consumidas (LUZ et al., 2009). Destaca-se pelo valor nutritivo, principalmente o alto teor de vitaminas A, B1, B2, B5 e C, sendo uma das principais fontes de provitamina A (TEÓFILO et al., 2009).

Dentre as olerícolas, a cenoura apresenta, a nível mundial, a quarta maior produção, com, aproximadamente, 37,2 milhões de toneladas (ANUÁRIO BRASILEIRO DE HORTALIÇAS, 2015). Dentre as hortaliças cuja parte comestível é a raiz tuberosa, a cenoura é a de maior valor econômico, além de propiciar geração de renda e empregos em todos os segmentos de sua cadeia produtiva, inclusive no controle de plantas infestantes. Várias espécies de plantas daninhas em cultivos de olerícolas apresentam alta concentração de AIA (ácido indolilacético), a exemplo da tiririca (Cyperus rotundus L.). Entretanto, são raras as pesquisas que experimentaram o extrato aquoso dessa espécie visando a aumentar a produção de raízes tuberosas como a cenoura.

A tiririca (C. rotundus L.) é uma planta daninha de difícil manejo e controle, causadora de prejuízos em diversas culturas comerciais, decorrentes da competição por água, luz e nutrientes durante o ciclo. Por se tratar de uma espécie perene, com ampla adaptabilidade em ambientes agrícolas, e pela capacidade de reproduzir sexuada e assexuadamente, a tiririca é considerada uma das espécies daninhas que mais causam prejuízos no mundo (PANOZZO et al., 2009). No Brasil, estima-se que metade dos solos agrícolas tenha infestação de tiririca (DURINGAN et al., 2005).

A tiririca apresenta elevados níveis dos ácidos indolacético (AIA) e indolbutírico (AIB), este último um fitorregulador que atua na formação das raízes das plantas, promovendo o enraizamento de estacas (DIAS et al., 2012). Também há relatos da presença de substâncias aleloquímicas no extrato de tiririca (CATUNDA et al., 2002), como fenóis, flavononas, saponinas e taninos. Conci (2004) observou presença de terpenos e esteroides, flavonoides, alcaloides e de taninos em extrato alcoólico de tiririca.

A utilização de extratos de $C$. rotundus $L$. no cultivo de cenoura pode propiciar maior valorização da produção, em virtude da possibilidade de antecipar o enraizamento, propiciando menor aplicação de defensivos e oferta de alimentos mais saudáveis. Além das vantagens citadas, o aproveitamento da tiririca pode ainda minimizar a aplicação de defensivos, contaminação do meio ambiente e redução de custos, por se tratar de uma espécie de planta daninha de difícil controle, sendo necessária a aplicação de altas dosagens de herbicidas.

Há evidências deque que o extrato aquoso de $C$. rotundus $L$. atua na regulação de substâncias do metabolismo vegetal, como no enraizamento de algumas espécies, de forma semelhante à utilização de auxinas sintéticas (CAVALCANTE et al., 2016; MAHMOUD et al., 2009; SOUZA et al., 2012).

Com relação às raízes tuberosas, são raras as pesquisas sobre o uso de fitormônios e melhor época de aplicação visando incrementar a produção de raízes. Considerando que a cenoura apresenta fases distintas, de crescimento vegetativo e de engrossamento da raiz, objetivouse avaliar o efeito de doses e épocas de aplicação do extrato de $C$. rotundus $L$. no desenvolvimento e produção de cenoura, cultivar Brasília.

\section{Material e Métodos}

O experimento foi desenvolvido na área experimental do Instituto Federal Catarinense Campus Concórdia, a $27^{\circ} 12^{\prime} 10.6^{\prime \prime} \mathrm{S}, 52^{\circ} 04^{\prime} 56.4^{\prime \prime} \mathrm{W}$, numa altitude de aproximadamente $569 \mathrm{~m}$, no período de setembro a dezembro de 2017. Conforme Köppen e Geiger, a classificação climática é $\mathrm{Cfa}$, denominado subtropical mesotérmico úmido, com verão quente. $\mathrm{A}$ temperatura média anual é de $18,4^{\circ} \mathrm{C}$ e a pluviosidade média, de $1.878 \mathrm{~mm}$. Durante o experimento, a temperatura média foi de $19^{\circ} \mathrm{C}$ e a pluviosidade, 474,2 mm (Figura 1). 
Figura 1. Dados meteorológicos registrados durante o período experimental. Instituto Federal Catarinense, Concórdia (SC), 2017.

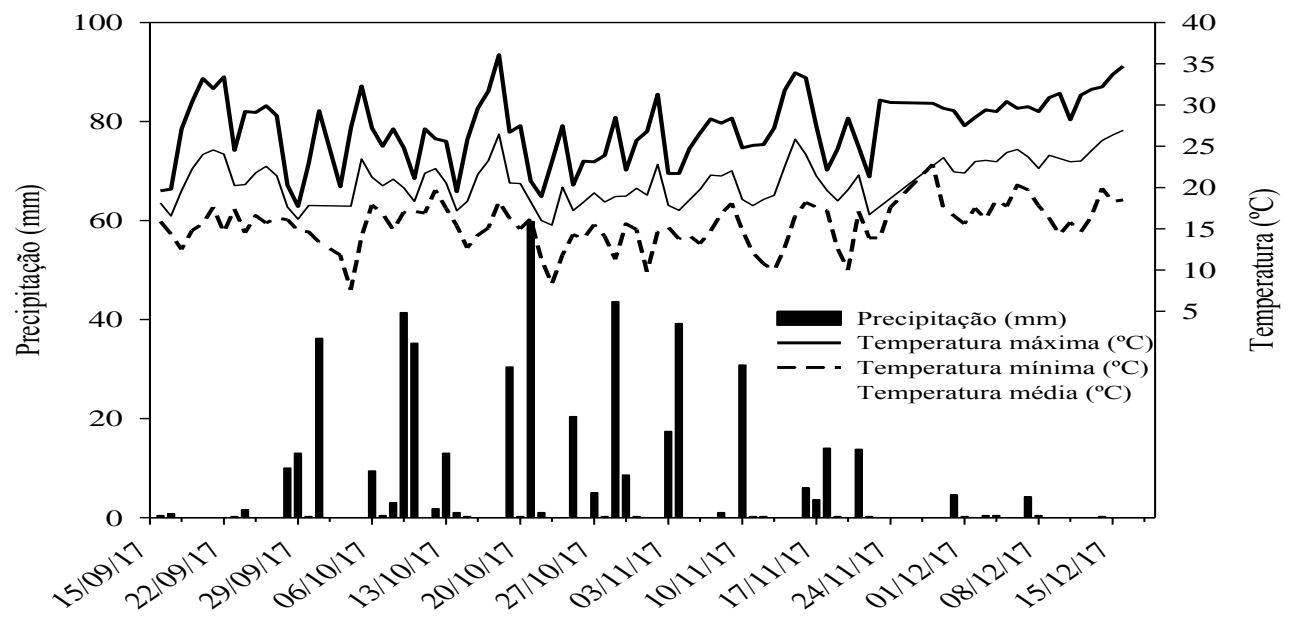

A área destinada ao experimento foi de 144 $\mathrm{m}^{2}$, sendo o solo classificado como latossolo vermelho, de textura muito argilosa (EMBRAPA, 2004). O preparo do solo foi realizado por meio de subsolador e encanteirador. Em antecedência ao experimento, foram realizadas análises químicas do solo para fins de adubação corretiva e implantação da cultura (Tabela 1).

Tabela 1. Atributos químicos do solo em antecedência à semeadura da cultura da cenoura, Concórdia (SC), 2017.

\begin{tabular}{ccccccccccc}
\hline $\mathrm{pH}$ & $\mathrm{P}$ & $\mathrm{K}$ & $\mathrm{P} . \mathrm{rem}$. & $\mathrm{MO}$ & $\mathrm{Ca}^{2+}$ & $\mathrm{Mg}^{2+}$ & $\mathrm{Al}^{3+}$ & $\mathrm{H}+\mathrm{Al}$ & $\mathrm{Na}$ & Enxofre \\
\hline $\mathrm{H}_{2} \mathrm{O}$ & $-------\mathrm{mg} \mathrm{L} \mathrm{L}^{-1}------$ & & $\%$ & & $-----\mathrm{cmol}_{\mathrm{C}} \mathrm{L}^{-1}---$ & & $\mathrm{ppm}$ & $\mathrm{mg} \mathrm{dm}^{-3}$ \\
6,7 & 18,5 & 299 & 32,7 & 3,6 & 7,2 & 4 & 0 & 1,9 & 9 & 11
\end{tabular}

Fonte: Solo Sul - Laboratório de Análise de Solos e Foliar, São João da Urtiga (RS)

De posse do laudo das análises químicas, e conforme as recomendações para a cultura da cenoura do Manual de Calagem e Adubação para RS e SC (CQFS, 2016), foram incorporadas ao solo, $10 \mathrm{t} \mathrm{ha}^{-1}$ de cama de galinha curtida, aos 10 dias antes da semeadura, e $40 \mathrm{~kg} \mathrm{ha}^{-1}$ de nitrogênio na forma de ureia, aplicados duas vezes, aos 30 e 45 dias após a semeadura. A cama de galinha foi analisada em laboratório e apresentou $60 \%$ de massa seca, 19,6 $\mathrm{g} \mathrm{kg}^{-1}$ de $\mathrm{N}, 15,5 \mathrm{~g} \mathrm{~kg}^{-1}$ de $\mathrm{P}_{2} \mathrm{O}_{5} \mathrm{e}$ $17,2 \mathrm{~g} \mathrm{~kg}^{-1}$ de $\mathrm{K}_{2} \mathrm{O}$.

As parcelas foram delimitadas com dimensões de 1,20 x $1 \mathrm{~m}$ de largura, espaçadas em $30 \mathrm{~cm}$ entre si. A semeadura foi realizada de forma manual, diretamente nos sulcos. Foram utilizados $200 \mathrm{~g}$ de sementes da cultivar Brasília (Feltrin ${ }^{\circ}$ ), sendo a profundidade de semeadura de aproximadamente $1,0 \mathrm{~cm}$, e o espaçamento entre os sulcos, de $20 \mathrm{~cm}$, contendo 4 linhas de um metro linear em cada parcela.
O delineamento experimental foi em blocos ao acaso com 4 repetições, em esquema fatorial $2 \times 5$, sendo duas épocas de aplicação (25 e 50 dias após semeadura) e cinco concentrações de extrato de tiririca $(0 \%, 10 \%, 20 \%, 30 \%$ e $40 \%)$, totalizando 40 parcelas.

Para obtenção do extrato aquoso, foram utilizados raízes e tubérculos de tiririca coletados em área do IFC - Campus Concórdia, SC. O material coletado foi lavado em água corrente e mantido à temperatura ambiente por vinte quatro horas. Em seguida, o material foi triturado em liquidificador, na proporção de $40 \mathrm{~g}$ de massa verde, medida em balança analítica, acrescentados $100 \mathrm{~mL}$ de água destilada. O material foi triturado por cinco minutos e, posteriormente, filtrado em peneira, obtendo-se o extrato bruto de $40 \%$. A partir do extrato bruto, foram feitas diluições para obter as demais concentrações, de $10 \%, 20 \%$ e $30 \%$, conforme metodologia de Scheren et al. (2014). Na 
concentração $0 \%$, foi aplicada apenas água destilada.

Após emergência, realizou-se o desbaste do excesso de plântulas no sulco de semeadura, mantendo espaçamento de $5 \mathrm{~cm}$ entre elas. A área útil foi constituída pelas duas linhas centrais de cada parcela. As linhas de plantas das extremidades foram consideradas bordaduras, assim como as cinco plantas no início e final das linhas.

A aplicação do extrato aquoso foi realizada por meio de regador, aos 25 dias após a semeadura, na metade das parcelas, e aos 50 dias após semeadura, na outra metade, aplicando 2,0 litros de extrato aquoso por parcela. Da semeadura ao início da germinação, a irrigação foi feita com maior frequência, duas vezes ao dia, manhã e tarde, com sistema de microaspersão, mantendo a umidade do solo próxima à capacidade de campo.

Os tratos culturais foram feitos manualmente, eliminando plantas infestantes à medida que emergiam. Atenção especial foi dada até os 25 dias após a semeadura por ser a fase em que a cultura necessita de maiores cuidados para evitar competição com plantas daninhas. Não foi aplicado nenhum tipo de defensivo para controle de pragas, doenças e plantas invasoras.

Aos 90 dias após a semeadura, realizou-se a colheita, de forma manual, evitando danos físicos às raízes. Em seguida, as mesmas foram lavadas e colocadas em caixas plásticas, identificadas e avaliadas. Foram avaliados os seguintes parâmetros, em dez plantas da área útil por parcela, sendo a massa seca obtida após secagem de raízes e parte aérea de plantas, em estufa de circulação de ar forçado a $65^{\circ} \mathrm{C}$ :

a) Diâmetro de raízes (DR, cm): medido com paquímetro, na porção mediana de raízes;

b) Altura de plantas $(\mathrm{AP}, \mathrm{cm})$ : obtida com régua, medida do colo até a extremidade da maior folha;

c) Massa fresca de raízes (MFR, g planta ${ }^{-1}$ ): obtida em balança digital, com precisão de 0,1 g;

d) Massa fresca da parte aérea (MFPA, g planta ${ }^{-1}$ );

e) Massa seca de raízes (MSR, g planta $^{-1}$ );

f) Massa seca total (MSTO, g planta ${ }^{-1}$ );

g) Massa seca média da parte aérea (MSPA, g planta $\left.{ }^{-1}\right)$;

h) Razão de massa seca de raiz e da parte aérea (MSR/MSPA, g planta ${ }^{-1}$ );

i) Comprimento de raiz $(\mathrm{CR}, \mathrm{cm})$ : medido do ápice até o colo com auxílio de uma régua; j) Produtividade comercial ( $\left.P C, \mathrm{t} \mathrm{ha}^{-1}\right)$ : com base nas dimensões das parcelas $(1,2 \times 1,0 \mathrm{~m})$, espaçamento entre plantas, número de canteiros por hectare, considerando $30 \mathrm{~cm}$ entre canteiros, estimou-se a população de plantas por hectare. $\mathrm{O}$ valor encontrado foi de 609.408 plantas ha $^{-1}$. Foram consideradas comerciais, raízes com diâmetro na parte mediana, igual ou superior a $3 \mathrm{~cm}$, e comprimento igual ou superior a $13 \mathrm{~cm}$, com ausência de deformação, ombro verde, rachaduras e ataque de insetos;

k) Massa de raízes com defeito (MRD, $\mathrm{t} \mathrm{ha}{ }^{-1}$ ): obtida por meio de pesagem das raízes que não atendiam o padrão de comercialização, apresentando qualquer um dos defeitos descritos;

I) Rendimento comercial (raízes $\mathrm{kg}^{-1}$ ): quantificouse o número de raízes necessários para obter $1,0 \mathrm{~kg}$ de raízes comerciais; e

m) Classificação de raízes por comprimento (CRC, $\mathrm{cm}$ ): as raízes foram classificadas em cinco classes comerciais, sendo: classe 10 - igual ou maior que $10 \mathrm{~cm}$ e menor que $14 \mathrm{~cm}$; classe 14 - igual ou maior que 14 e menor que 18 $\mathrm{cm}$; classe 18 - igual ou maior que $18 \mathrm{~cm}$ e menor que $22 \mathrm{~cm}$; classe 22 - igual ou maior de 22 e menor de $26 \mathrm{~cm}$; e cenouras igual ou acima de $26 \mathrm{~cm}$ estarão na classe 26 (CEAGESP, 2015).

As análises foram realizadas no software $R$ 3.5.0, com auxílio dos pacotes ExpeDes.pt e Agricolae. Para testar a homogeneidade e a normalidade dos resíduos, foram aplicados os testes de Bartlett e de Shapiro Wilk, respectivamente. Com os pressupostos atendidos, procedeu-se a análise de variância (ANOVA), aplicando o teste F. Os parâmetros que apresentaram efeito significativo $((p<0,05)$ às épocas de aplicação do extrato, foram comparadas pelo teste de Tukey, enquanto as concentrações do extrato foram comparadas por meio de equações de regressão.

\section{Resultados e Discussão}

As épocas de aplicação influenciaram significativamente $(p<0,05)$ todos os parâmetros avaliados, com exceção da altura das plantas. As doses do extrato de tiririca também apresentaram significância $(p<0,05)$ para as massas fresca e seca da parte aérea, massa seca total, razão entre massa seca de raiz e da parte aérea (MSR/MSPA), comprimento de raiz e massa de raízes com defeito. Houve interação $(p<0,05)$ 
entre os tratamentos de doses e épocas para altura de plantas, massa fresca e seca da parte aérea, massa seca total, relação MSR/MSPA e massa de raízes com defeitos (Tabela 2).

Tabela 2. Resumo das análises de variância do diâmetro de raiz $(\mathrm{DR}, \mathrm{cm})$, altura de plantas $(\mathrm{AP}, \mathrm{cm})$, massa fresca de raiz (MFR), massa fresca da parte aérea (MFR, g planta ${ }^{-1}$ ), massa seca de raiz (MSR, g planta ${ }^{-1}$ ), massa seca da parte aérea (MSPA, g planta ${ }^{-1}$ ), massa seca total (MSTO, g planta ${ }^{-1}$ ), razão MSR/MSPA, comprimento de raiz $(C R, \mathrm{~cm})$, produtividade comercial $\left(\mathrm{PC}, \mathrm{t}\right.$ ha $\left.{ }^{-1}\right)$, massa de raízes com defeito (MRD, $t$ ha ${ }^{1}$ ), produtividade total $\left(\mathrm{PT}, \mathrm{t} \mathrm{ha}{ }^{-1}\right)$ e rendimento comercial $\left(\mathrm{RC}\right.$, raízes $\left.\mathrm{kg}^{-1}\right)$ da cenoura $\mathrm{cv}$. Brasília, em função de épocas de aplicação e doses do extrato de tiririca. Concórdia - SC, 2017

\begin{tabular}{|c|c|c|c|c|c|c|c|c|c|c|c|c|c|c|}
\hline \multirow{2}{*}{$\begin{array}{l}\text { Fonte de } \\
\text { Variação }\end{array}$} & \multirow[b]{2}{*}{ GL } & \multicolumn{13}{|c|}{ F calculado } \\
\hline & & DR & $A P$ & MFR & MFPA & MSR & MSPA & MST & $\mathrm{MSR} / \mathrm{M}$ & CR & PC & URD & PT & $\mathrm{RC}$ \\
\hline $0 \Omega$ & 3 & $2,72^{*}$ & & $1,60^{\mathrm{ns}}$ & $3,1^{*}$ & $3,13^{\text {ns }}$ & & $2,0^{\text {ns }}$ & & $1,70^{\mathrm{ns}}$ & & & & 12 \\
\hline & 1 & $25,61^{*}$ & 2,9 & $60,53^{*}$ & $308,3^{*}$ & $33,5^{*}$ & $323,7^{*}$ & ${ }^{*} 185,9^{*}$ & & $11,66^{*}$ & & & & 32,0 \\
\hline Dse & 4 & $1,54^{\mathrm{ns}}$ & & $1,77^{\mathrm{ns}}$ & $53,4^{*}$ & $1,7^{\text {ns }}$ & $32,5^{*}$ & $16,52^{*}$ & $14,95^{*}$ & $2,62^{*}$ & $9^{\text {ns }}$ & 2 & ${ }^{*} 1,7$ & 2,49 \\
\hline$x$ & 4 & ns & & $0,62^{\mathrm{ns}}$ & $8,3^{*}$ & $0,87^{\text {ns }}$ & $15,4^{*}$ & 2,9 & 8, & $1,92^{\mathrm{ns}}$ & 0,6 & & $0,62^{\mathrm{ns}}$ & 0,5 \\
\hline & & & & 277 & & & & & & & & 21,24 & & \\
\hline lédia & & 3,27 & 63,43 & 108,9 & 49,24 & 12,46 & 26,20 & 270,6 & 0,49 & 14,68 & 65,01 & 1,39 & 63,90 & 10,1 \\
\hline
\end{tabular}

$\mathrm{CV}=$ coeficiente de variação, ns $=$ não significativo, ${ }^{*}=$ significativo a $5 \%$ de probabilidade pelo teste

Comparando as duas épocas de aplicação do extrato, aos 25 e 50 dias, independentemente da dose, a aplicação do extrato aos 50 dias após a semeadura da cenoura apresentou melhores resultados para todas as variáveis analisadas, exceto para MSR, não se diferindo pelo teste de Tukey a $5 \%$ de probabilidade (Tabela 3 ).

Tabela 3. Médias do diâmetro de raízes ( $D R, \mathrm{~cm}$ ), massa fresca de raiz (MFR, $\mathrm{g}$ planta ${ }^{-1}$ ), massa seca de raiz (MSR, g planta $\left.{ }^{-1}\right)$, comprimento de raiz $(\mathrm{CR}, \mathrm{cm})$, produtividade comercial $\left(\mathrm{PC}, \mathrm{t} \mathrm{ha}^{-1}\right)$, produtividade total $\left(\mathrm{PT}, \mathrm{t} \mathrm{ha}{ }^{-1}\right)$ e rendimento comercial $\left(\mathrm{RC}\right.$, raízes $\left.\mathrm{kg}^{-1}\right)$ da cenoura $\mathrm{cv}$. Brasília, aos 90 dias após semeadura, em função de épocas de aplicação do extrato de tiririca. Concórdia - SC, 2017

\begin{tabular}{cccccccc} 
Épocas & DR & MFR & MSR & CR & PC & PT & RC \\
\hline 25 dias & $3,16 \mathrm{~b}$ & $97,18 \mathrm{~b}$ & $12,07 \mathrm{a}$ & $14,01 \mathrm{~b}$ & $56,8 \mathrm{~b}$ & $58,1 \mathrm{~b}$ & $11,40 \mathrm{~b}$ \\
50 dias & $3,37 \mathrm{a}$ & $120,74 \mathrm{a}$ & $12,84 \mathrm{a}$ & $15,36 \mathrm{a}$ & $68,2 \mathrm{a}$ & $69,7 \mathrm{a}$ & $8,82 \mathrm{a}$ \\
\hline Média: & 3,27 & 108,96 & 12,46 & 14,68 & 65,01 & 63,90 & 10,11 \\
\hline
\end{tabular}

Médias seguidas de mesma letra nas colunas, não diferem entre si pelo teste de Tukey $(p<0,05)$

Possivelmente, a aplicação do extrato aos 25 dias tenha ocasionado maior efeito alelopático ao desenvolvimento radicular da cenoura, ocasionando menor DR, MFR, CR e produção de raízes, em comparação ao uso do extrato aos 50 dias. Tal evidência foi confirmada em estudos de Scherem et al. (2014) em milho, autores estes que verificaram que o extrato aplicado antes da semeadura em caixas gerbox, na concentração de $7,5 \%$, não influenciou no crescimento da radícula e parte aérea de plântulas de milho, enquanto na concentração de $30 \%$ inibiu significativamente o crescimento desses parâmetros. Deomedesse et al. (2019) também observaram que o extrato de tubérculos de tiririca (Cyperus rotundus L.), apresentou potencial alelopático na germinação e no vigor das sementes de alface, pepino, milhodoce e corda-de-viola.

O desdobramento de épocas para cada dose do extrato apresentou diferença na altura de plantas apenas nas doses de $30 \%$ e $40 \%$, tendo a aplicação do extrato aos 50 dias propiciado maior desenvolvimento da parte aérea (Tabela 4). Independentemente da dose aplicada de extrato de tiririca, as maiores massas fresca e seca da parte aérea e massa seca total foram presenciadas quando o extrato foi aplicado aos 50 dias. Como a produtividade total de raízes foi de 
$69,7 \mathrm{t} \mathrm{ha}^{-1}$ aos 50 dias, esse dado apresenta correlação com a maior massa de raízes com defeitos, em comparação à aplicação do extrato aos 25 dias, em todas as doses do extrato, exceto a dose de $10 \%$, em que as duas épocas não diferiram entre si.

Tabela 4. Desdobramento de épocas de aplicação em cada dose do extrato de tiririca, para os parâmetros de altura de plantas (AP, $\mathrm{cm})$, massa fresca da parte aérea (MFPA, g planta $\left.{ }^{-1}\right)$, massa seca da parte aérea (MSPA, g planta ${ }^{-1}$ ), massa seca total (MSTO, g planta ${ }^{-1}$ ), razão entre a massa seca de raiz e da parte aérea (MSR/MSPA) e massa de raízes com defeitos (MRD, $\mathrm{t}$ ha $^{-1}$ ) da cenoura cv. Brasília, aos 90 dias após semeadura. Concórdia - SC, 2017

\begin{tabular}{|c|c|c|c|c|c|c|c|}
\hline \multirow[b]{2}{*}{$\begin{array}{c}\text { Parâmetros } \\
\text { avaliados }\end{array}$} & \multirow{2}{*}{$\begin{array}{c}\text { Época de } \\
\text { aplicação (dias } \\
\text { após } \\
\text { semeadura) }\end{array}$} & \multicolumn{5}{|c|}{ Doses } & \multirow[b]{2}{*}{ Média: } \\
\hline & & $0 \%$ & $10 \%$ & $20 \%$ & $30 \%$ & $40 \%$ & \\
\hline \multirow{2}{*}{ AP } & 25 & 61,89 a & $64,92 \mathrm{a}$ & $66,03 \mathrm{a}$ & $61,14 b$ & $59,50 \mathrm{~b}$ & 62,70 \\
\hline & 50 & $63,50 \mathrm{a}$ & $63,07 \mathrm{a}$ & $63,50 \mathrm{a}$ & $66,08 \mathrm{a}$ & $64,68 \mathrm{a}$ & 64,16 \\
\hline \multirow{2}{*}{ MFPA } & 25 & $48,80 \mathrm{~b}$ & $42,16 \mathrm{~b}$ & $52,41 \mathrm{~b}$ & $38,54 \mathrm{~b}$ & $41,32 \mathrm{~b}$ & 44,65 \\
\hline & 50 & $55,98 \mathrm{a}$ & 49,72 a & $57,38 a$ & $50,83 \mathrm{a}$ & $55,30 \mathrm{a}$ & 53,84 \\
\hline \multirow{2}{*}{ MSPA } & 25 & $8,93 \mathrm{~b}$ & $7,77 \mathrm{~b}$ & $7,08 \mathrm{~b}$ & $6,76 \mathrm{~b}$ & $6,05 \mathrm{~b}$ & 7,32 \\
\hline & 50 & $9,11 \mathrm{a}$ & $8,46 \mathrm{a}$ & $7,84 \mathrm{a}$ & $7,89 \mathrm{a}$ & $8,02 \mathrm{a}$ & 8,26 \\
\hline \multirow{2}{*}{ MSTO } & 25 & $22,66 \mathrm{a}$ & $19,98 \mathrm{~b}$ & $18,54 \mathrm{~b}$ & $18,27 \mathrm{~b}$ & $17,50 \mathrm{~b}$ & 19,39 \\
\hline & 50 & $20,25 \mathrm{~b}$ & 20,78 a & $21,50 \mathrm{a}$ & 21,49 a & 21,33 a & 21,07 \\
\hline \multirow{2}{*}{ MSR/MSPA } & 25 & $0,49 a$ & $0,52 \mathrm{a}$ & $0,44 \mathrm{a}$ & $0,60 \mathrm{a}$ & $0,50 \mathrm{a}$ & 0,51 \\
\hline & 50 & $0,46 a$ & $0,53 a$ & $0,47 \mathrm{a}$ & $0,46 \mathrm{~b}$ & $0,44 \mathrm{~b}$ & 0,47 \\
\hline \multirow{2}{*}{ MRD } & 25 & $1,5 \mathrm{~b}$ & $1,3 \mathrm{a}$ & $1,2 \mathrm{~b}$ & $1,0 \mathrm{~b}$ & $1,3 \mathrm{~b}$ & 1,30 \\
\hline & 50 & $1,8 \mathrm{a}$ & $1,4 a$ & $1,7 \mathrm{a}$ & $1,3 \mathrm{a}$ & $1,5 \mathrm{a}$ & 1,50 \\
\hline
\end{tabular}

Médias seguidas de mesma letra nas colunas, para cada parâmetro avaliado, não diferem entre si pelo teste de Tukey $(\mathrm{p}<0,05)$

O modelo de equação quadrático apresentou melhor ajuste para altura das plantas (AP) em função de doses do extrato aos 25 e aos 50 dias (Figuras 2A e 2B). Houve incrementos na altura das plantas até as concentrações de $17,3 \%$ e $22,9 \%$ do extrato, sendo a AP estimada em 65,6 $\mathrm{cm}$ para as duas épocas de aplicação. Apesar da interação significativa das doses e épocas, constatou-se que a máxima altura de planta foi semelhante para aplicações ao 25 e 50 dias.

$\mathrm{O}$ uso do extrato tende a inibir a altura de planta nas maiores concentrações, de $30 \%$ e $40 \%$, podendo assumir que, para as condições desta pesquisa, as concentrações de $17,3 \%$ a $22,9 \%$ proporcionaram maior altura de planta. Esses resultados são condizentes com os de Moreira e Giglio (2012), que, utilizando extrato de tiririca em sementes de trigo, observaram efeito positivo na altura da parte aérea e no peso das plântulas, sendo a melhor concentração do extrato igual a $12,5 \%$. 
Figura 2. Altura de plantas (A e B), massa fresca da parte aérea ( $C$ e $D$ ) e massa seca da parte aérea (E e $F$ ) de cenoura aos 90 dias, em função de doses de extrato de tiririca aplicado aos 25 e 50 dias após semeadura. IFC - Campus Concórdia, 2017
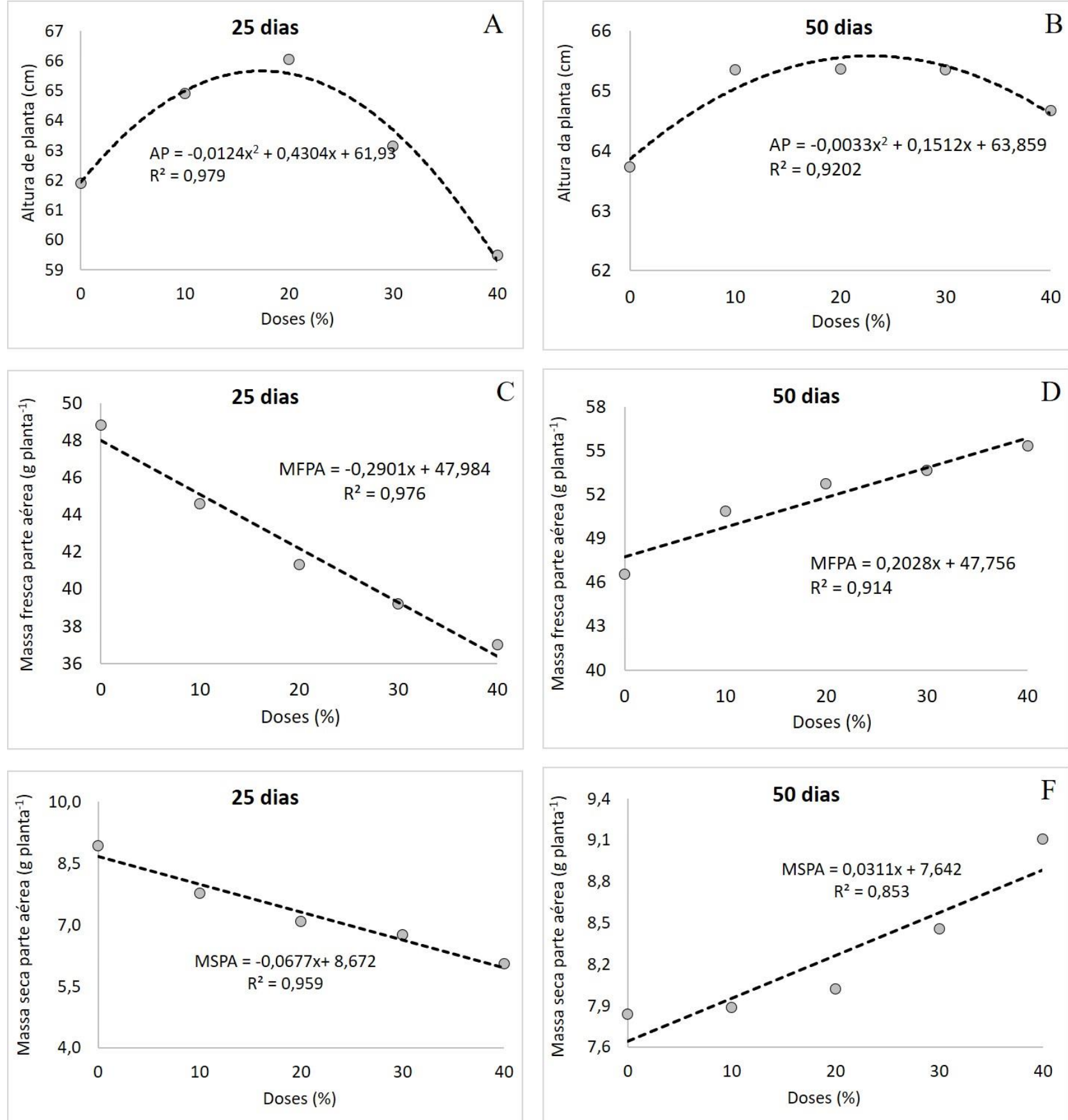

Em pesquisa desenvolvida por Zanella e Moreira (2013), a altura de plantas de cenoura cv. Nantes apresentou valor máximo de $41,5 \mathrm{~cm}$. Todavia, Resende e Braga (2014), avaliando o desempenho de cultivares de cenoura, obtiveram altura de plantas da cultivar Brasília de $64,1 \mathrm{~cm}$, valores esses que variam sobretudo conforme a cultivar e o teor de nitrogênio no solo, havendo menor influência das auxinas AIA e AIB.

Com relação à massa fresca da parte aérea (MFPA), houve efeito linear decrescente das

doses na aplicação ao 250 dia. O uso de apenas de apenas água, com ausência da solução de tubérculos de tiririca, propiciou maior MFPA, enquanto, à medida que foram aumentadas as concentrações do extrato, houve redução da MFPA em $0,29 \mathrm{~g}$ planta $^{-1}$ para cada $1 \%$ de acréscimo da concentração (Figuras $2 \mathrm{C}$ e $2 \mathrm{D}$ ). Por outro lado, aplicando o extrato ao 50 dia, para cada $1 \%$ de aumento na concentração, houve incremento de $0,2 \mathrm{~g}$ planta $^{-1}$ na MFPA. 
Houve expressiva redução da MFPA após sua secagem em estufa de circulação forçada de ar, principalmente nas maiores concentrações do extrato. Para cada $1 \%$ de extrato aplicado ao 25 o dia, houve decréscimo na MSPA de 0,0677 g planta $^{-1}$. Aplicando o extrato ao 50 o dia, para cada $1 \%$ de aplicação de extrato, houve aumento de 0,0311 g planta $^{-1}$ da MSPA (Figuras 2E e 2F). A aplicação de apenas água aos 25 dias favoreceu $O$ desenvolvimento da parte aérea. Por outro lado, as doses com extrato provavelmente apresentaram efeitos alelopáticos, tendo os compostos fenólicos ocasionado inibição tanto do desenvolvimento radicular quanto da parte aérea.

Souza et al. (2020), utilizando extrato aquoso de tiririca a $0 \%, 25 \%, 50 \%$ e $100 \%$ em alface, observaram que a concentração de $100 \%$ ocasionou efeito alelopático, resultando menor crescimento da parte aérea, menor quantidade de folhas e teor de clorofila. Entretanto, nessa concentração propiciou maior desenvolvimento do sistema radicular, sendo esta umas das evidências de que o extrato apresenta auxinas, como o ácido indolacético, em sua composição.

A aplicação do extrato concentrado a $40 \%$, ao 25 ㅇ dia, ocasionou redução de $22,7 \%$ na massa seca total (MSTO) das plantas de cenoura, em comparação à dose zero, com aplicação apenas de água, o que demonstra possíveis efeitos alelopáticos de compostos fenólicos ao aumentar a concentração do extrato. Por outro lado, aplicando o extrato ao 50 dia após semeadura, no início da fase de engrossamento de raiz, houve resposta linear crescente da MSTO com o aumento da concentração do extrato. Para cada $1 \%$ de extrato aplicado, foi estimado aumento de 0,089 g planta $^{-1}$ na MSTO (Figura 3A e 3B). A MSTO não segue a mesma linha de tendência da MSPA por ter sido composta principalmente pela massa seca de raízes.

A razão entre as massas de matéria seca de raiz e da parte aérea (MSR/MSPA) apresentou melhor resposta nas maiores doses do extrato, em ambas as épocas de aplicação. Ao 250 dia, a maior relação MSR/MSPA foi de 1,88, obtida na dose de extrato igual a $40 \%$. A equação de 20 grau indica que, aplicando o extrato na fase de 50 dias, a maior relação MSR/MSPA é estimada em 1,67 , com uma dose ótima do extrato equivalente a $21,0 \%$ (Figuras 3C e 3D).

Figura 3. Massa seca total ( $A$ e $B$ ) e razão das massas seca de raízes e da parte aérea ( $C$ e $D$ ) de plantas de cenoura aos 90 dias, em função de doses de extrato de tiririca, aplicadas aos 25 e 50 dias após semeadura (B). IFC - Campus Concórdia, 2017
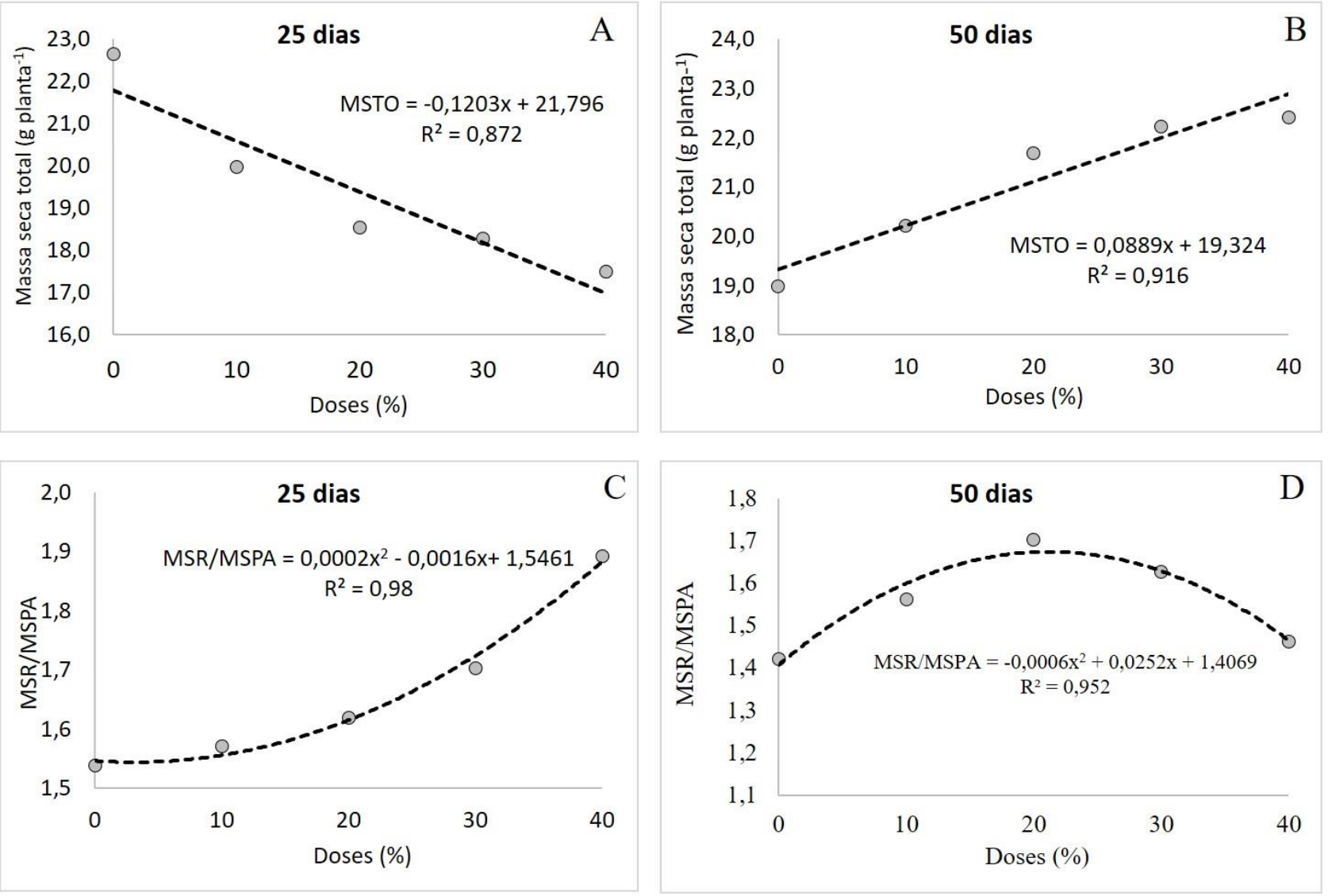
A alta razão MSR/MSPA em maior concentração do extrato é condizente com o trabalho de Mahmoud et al. (2009) sobre olerícola de raiz tuberosa. Esses autores fizeram a imersão de manivas de mandioca em diferentes soluções e verificaram que a auxina natural extraída do tubérculo da tiririca promoveu maior quantidade de raízes de mandioca, em comparação à auxina sintética AIB. Os resultados de ambas as pesquisas dão indícios de que o extrato aquoso de tiririca apresenta quantidade de auxinas AIA e AIB suficiente para promover maior produção de raízes, influenciando, principalmente, no engrossamento da raiz de cenoura.

Independentemente da época de aplicação do extrato de Cyperus rotundus L., o sistema radicular da cenoura apresentou redução no comprimento com o aumento da dose, até a concentração de 26,8\% (Figura 4), sendo estimado o menor CR, de $13,9 \mathrm{~cm}$. Em trabalho desenvolvido por Zanella e Moreira (2013), o maior comprimento de raiz da cenoura cv. Nantes foi estimado em 13,94 cm, valor próximo aos encontrados neste trabalho com a cv. Brasília. Os resultados obtidos são condizentes aos de Araújo et al. (2011), ao constatarem que o extrato de Cyperus rotundus L. também reduziu o crescimento do sistema radicular da cenoura a partir da concentração de $10 \%$. Por outro lado, Rodrigues et al. (2020) não observaram efeito do extrato de tiririca, em concentrações de $25 \%$, $50 \%, 75 \%$ e $100 \%$ no enraizamento adventício de estacas de limão Tahiti. Verifica-se, portanto, que nas diferentes concentrações do extrato, cada espécie responde de forma na formação de raízes, sejam elas adventícias ou tuberosa, sendo necessários outras pesquisas sobre o tema.

Figura 4. Comprimento de raiz (CR) de cenoura aos 90 dias, em função de doses de extrato de tiririca, IFC Campus Concórdia, 2017

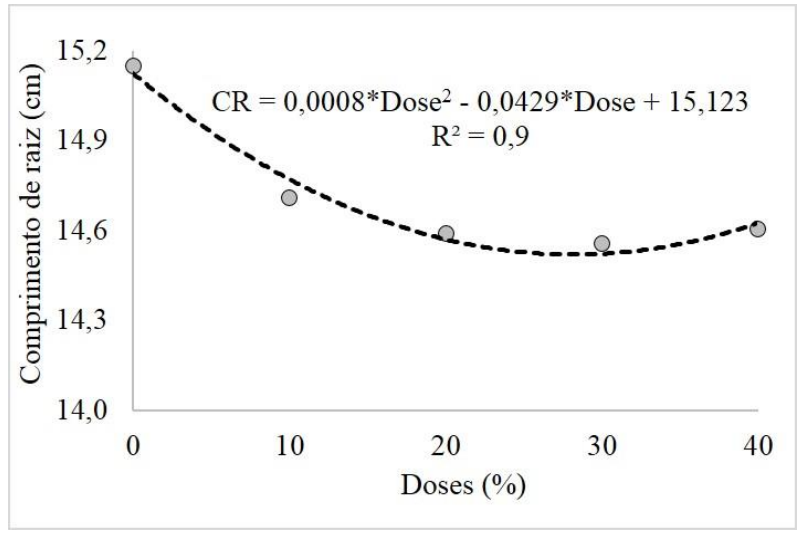

Utilizando o extrato em outras espécies, Ribeiro et al. (2014) concluíram que o extrato de tiririca, em menor concentração, de apenas 7,5\%, ocasionou maior crescimento radicular e da parte aérea de plântulas de milho. Já, Cavalcante et al. (2018), fazendo embebição de sementes de rabanete no extrato aquoso a $25 \%$, constataram aumento na velocidade de germinação e maior desenvolvimento inicial de plântulas. Verificaram também tendência de maior comprimento da raiz tuberosa de rabanete à medida que aumentaram as concentrações do extrato, de $25 \%$ a $100 \%$.

Por outro lado, Moreira e Giglio (2012) verificaram que o uso de extrato de tiririca em sementes de trigo não surtiu efeito no comprimento da raiz. Pesquisa desenvolvida por
Andrade et al. (2009), em várias espécies olerícolas, constatou que o sistema radicular foi a estrutura vegetal mais influenciada pelo extrato de folhas secas de tiririca, provavelmente devido à presença de auxinas e por estar em contato direto com o extrato aquoso.

Cavalcante et al. (2016) constataram que o uso do extrato aquoso de tiririca na concentração de 100\%, na embebição de sementes de beterraba, favoreceu o desenvolvimento inicial das plântulas, elevando a velocidade de germinação e o desenvolvimento da raiz principal, quando comparada ao uso da auxina sintética AIB. Como nesta pesquisa o extrato foi aplicado apenas ao 25 e 50 dia, não é possível estabelecer uma comparação direta entre 
aplicação do extrato no tratamento de sementes e aplicação do extrato com regador e, também por se referir a duas fases distintas de desenvolvimento, a de crescimento vegetativo e a de engrossamento de raiz.

Cavalcante et al. (2018) verificaram que a concentração de $25 \%$ do extrato de tiririca foi eficiente para a germinação e o comprimento da raiz principal de plântulas de rabanete quando aplicado na embebição de sementes. Possivelmente, esse efeito se deve à presença de ácido indolbutírico (AIB), pois em outro experimento os autores também constataram melhores resultados aplicando 0 hormônio sintético AIB na concentração de $1,5 \mathrm{~g} \mathrm{~L}^{-1}$.

A classificação das raízes de cenoura por comprimento $(\mathrm{cm})$ não apresentou raízes com comprimento superior a $26 \mathrm{~cm}$, sendo a maioria das raízes comerciais da classe 18 , em ambas as épocas de aplicação do extrato. Apenas a dose de $40 \%$ aplicada aos 50 dias apresentou raízes pertencentes à classe 22 (Tabela 5).

Tabela 5. Classificação das raízes comerciais de cenoura aos 90 dias, por comprimento (cm), em função de épocas de aplicação de extrato aquoso de tiririca, aos 25 e 50 dias após semeadura.

\begin{tabular}{|c|c|c|c|c|c|c|c|c|c|c|}
\hline & \multicolumn{2}{|c|}{ Classe 10} & \multicolumn{2}{|c|}{ Classe 14} & \multicolumn{2}{|c|}{ Classe 18} & \multicolumn{2}{|c|}{ Classe 22} & \multicolumn{2}{|c|}{ Classe 26} \\
\hline & 25 dias & 50 dias & 25 dias & 50 dias & 25 dias & 50 dias & 25 dias & 50 dias & 25 dias & 50 dias \\
\hline & \multicolumn{10}{|c|}{$\mathrm{t} \mathrm{ha}^{-1}$} \\
\hline$\overline{0 \%}$ & $19,2 \mathrm{eB}$ & $22,4 \mathrm{dA}$ & 35,5 aA & $29,9 \mathrm{eB}$ & $4,5 \mathrm{bB}$ & $7,5 \mathrm{aA}$ & 0,0 & 0,0 & 0,0 & 0,0 \\
\hline $10 \%$ & $21,6 \mathrm{~dB}$ & $27,2 \mathrm{aA}$ & 31,6 bA & $30,4 \mathrm{~dB}$ & $4,3 \mathrm{cB}$ & $6,4 \mathrm{cA}$ & 0,0 & 0,0 & 0,0 & 0,0 \\
\hline $20 \%$ & 29,9 aA & $26,5 \mathrm{bB}$ & $25,7 \mathrm{eB}$ & $37,1 \mathrm{cA}$ & $1,4 \mathrm{eB}$ & 7,1 bA & 0,0 & 0,0 & 0,0 & 0,0 \\
\hline $30 \%$ & $23,8 \mathrm{cA}$ & 21,6 eB & $26,6 \mathrm{~dB}$ & 48,6 aA & $5,6 \mathrm{aA}$ & $1,8 \mathrm{eB}$ & 0,0 & 0,0 & 0,0 & 0,0 \\
\hline $40 \%$ & $24,7 \mathrm{bA}$ & $24,3 \mathrm{cB}$ & $27,4 \mathrm{cB}$ & $43,0 \mathrm{bA}$ & $2,8 \mathrm{~dB}$ & $5,7 \mathrm{dA}$ & 0,0 & 1,9 & 0,0 & 0,0 \\
\hline Média & 23,8 & 24,4 & 29,4 & 37,8 & 3,7 & 5,7 & 0,0 & 0,4 & 0,0 & 0,0 \\
\hline
\end{tabular}

Médias seguidas da mesma letra maiúscula na linha, em cada classe, não diferem entre si pelo teste Tukey $(p<0,05)$. Médias seguidas da mesma letra minúscula na coluna não diferem entre si pelo teste Tukey $(p<0,05)$

Considerando as três menores classes de tamanho (classes 10, 14 e 18), nas concentrações de $20 \%$, $0 \%$ e $30 \%$, aplicadas aos 25 dias, foram observadas as maiores produtividades comerciais, respectivamente. Aplicando as doses aos 50 dias, as maiores produtividades comerciais por classe foram de 27,2 $\mathrm{t} \mathrm{ha}^{-1}$ (classe 10), de 48,6 $\mathrm{t} \mathrm{ha}^{-1}$ (classe 14) e de $7,5 \mathrm{t} \mathrm{ha}^{-1}$ (classe 18), valores obtidos com as concentrações de $10 \%, 30 \%$ e $0 \%$ do extrato de tiririca, respectivamente. Observouse que, na época de 50 dias, foram obtidas, em média, cenouras de maior comprimento.

\section{Conclusões}

Nas condições edafoclimáticas do experimento, a aplicação do extrato aos 50 dias foi mais eficiente na maioria dos parâmetros, com menor efeito alelopático.

Não houve efeito significativo das concentrações do extrato na produtividade comercial e total de raízes.

Maior quantidade de raízes para ambas as épocas de aplicação do extrato foi quantificada na classe 14.
Sugere-se novas pesquisas sobre o tema, visando mais informações sobre época de aplicação e parcelamento de doses do extrato aquoso de tiririca na cultura de cenoura.

\section{Referências}

ANDRADE, H. M.; BITTENCOURT, A. H. C.; VESTENA, S. Potencial alelopático de Cyperus rotundus L. sobre espécies cultivadas. Ciência e Agrotecnologia, v.33, esp., p.1984-1990, 2009. https://doi.org/10.1590/S1413$\underline{70542009000700049}$

ANUÁRIO BRASILEIRO DE HORTALIÇAS. As principais: cenoura. Santa Cruz do Sul: Gazeta, $2015 . \quad$ p.38-41. Disponível em: http://www.grupogaz.com.br/tratadas/eo edicao 6/2015/06/20150616 b08a18fce/pdf/4814 hortali cas 2015.pdf . Acesso em: 09 jan. 2021.

ANUÁRIO BRASILEIRO DE HORTALIÇAS. Cenoura carrot: para não ficar ralado. Santa Cruz do Sul, RS. Editora Gazeta, 2017. p.41. Disponível em http://www.editoragazeta.com.br/flip/anuario- 
hortalicas-2017/files/assets/basic-

html/page43.html . Acesso em: 09 jan. 2021.

ARAÚJO, F. C. M.; FAGUNDES, R. S.; MOREIRA, G. $C$. Índice de germinação e protusão primária das raízes de sementes de cenoura submetidas ao extrato de tiririca. Cultivando o Saber, v.4, n.3, p.103-108, 2011.

CATUNDA, M. G.; SOUZA, C. L. M.; MORAIS, V.; CARVALHO, G. J. A.; FREITAS, S. P. Efeitos de extratos aquosos de tiririca (Cyperus rotundus L.) sobre a germinação de alface, pimentão, e jiló e sobre a divisão celular na radícula da alface. Revista Ceres, Viçosa, v.49, n.281, p.1-11, 2002. http://www.ceres.ufv.br/ojs/index.php/ceres/arti cle/download/2785/64555

CAVALCANTE, J. A.; LOPES, K. P.; PEREIRA, N. A. E.; PAIVA, L. G.; ABRANTES, J. V. Bioativadores naturais no desempenho fisiológico de sementes de beterraba. Revista de la Facultad de Agronomía, La Plata, v.115, n.2, p.229-237, 2016. http://revista.agro.unlp.edu.ar/index.php/revagro Larticle/view/359/420

CAVALCANTE, J. A.; LOPES, K. P.; PEREIRA, N. A. E.; SILVA, J. G.; PINHEIRO, R. M.; MARQUES, R. L. L. Extrato aquoso de bulbos de tiririca sobre a germinação e crescimento inicial de plântulas de rabanete. Revista Verde de Agroecologia e Desenvolvimento Sustentável, v.13, n.1, p.39-44, 2018. https://doi.org/10.18378/rvads.v13i1.5701

CEAGESP. Normas de classificação: cenoura (Daucus carota L.). São Paulo: Programa Brasileiro para a Modernização da Horticultura, 2015. 5p.

(Folder). Disponível em:

http://www.ceagesp.gov.br/wpcontent/uploads/2015/07/cenoura.pdf . Acesso em: 06 jan. 2021.

CONCI, F. R. Utilização de extrato aquoso e alcoólico de Cyperus rotundus (tiririca) como fitorregulador de enraizamento de Lagerstroemia indica (Extremosa) e da Hydrangea macrophila (Hortênsia). 2004. 44p. Monografia (Graduação em Agronomia) Universidade Comunitária Regional de Chapecó, Chapecó-SC, 2004.

CQFS. Manual de calagem e adubação para os Estados do Rio Grande do Sul e de Santa
Catarina. 11. ed. Sociedade Brasileira de Ciência do Solo, Núcleo Regional Sul, 2016. 376 p.

DEOMEDESSE, C. C.; MENESES, N. B.; SOUSA, G. O.; SILVA, T. S.; CRUZ, G. A. Efeitos alelopáticos de extrato de tiririca na germinação de milho-doce, alface, pepino e corda-de-viola. Magistra, v.30, p.323-330, 2019. https://magistraonline.ufrb.edu.br/index.php/ma gistra/article/view/693

DIAS, J. R. M.; SILVA, E. A.; GONÇALVES, G. S.; SILVA, J. F.; SOUZA, E. F. M.; FERREIRA, E.; STACHIW, R. Enraizamento de estacas de cafeeiro imersas em extrato aquoso de tiririca. Universidade Federal de Rondônia. Coffee Science, v.7, n.3, p.259-266, 2012.

DURINGAN, J. C.; TIMOSSI, P. C.; CORREIA, N. M. Densidades e manejo químico da tiririca na produtividade de cana-de-açúcar. Planta Daninha, v.23, n.3, p.463-469, 2005. https://doi.org/10.1590/\$0100$\underline{83582005000300010}$

EMBRAPA. Solos do estado de Santa Catarina, Rio de Janeiro: Embrapa Solos, 2004. (Boletim de Pesquisa e Desenvolvimento, 46). Disponível em: https://www.infoteca.cnptia.embrapa.br/ handle/doc/964417 . Acesso em: 15 jul. 2018.

LUZ, J. M. Q.; ZORZAL FILHO, A.; RODRIGUES, W. L.; RODRIGUES, C. R.; QUEIROZ, A. A. Adubação de cobertura com nitrogênio, potássio e cálcio na produção comercial de cenoura. Horticultura Brasileira, v.27, p.543-548, 2009. https://doi.org/10.1590/S0102$\underline{05362009000400023}$

MAHMOUD, T. S.; SANTOS, A. H.; SCHUROFF, I. A.; SANTOS, H. C. X. M. Avaliação do efeito de hormônio natural, sintético e indutor no desenvolvimento da primeira fase de brotação das estacas de Manihot esculenta Crantz. In: Congresso Brasileiro de Mandioca, 8. Resumos Expandidos [...]. Botucatu, 2009. p.621-625. http://energia.fca.unesp.br/index.php/rat/article/ view/1409/728

MOREIRA, G. C.; GIGLIO, L. C. Uso de extrato de tiririca em sementes de milho e trigo. Cultivando o Saber, v.5, n.3, p.89-99, 2012. 
PANOZZO, L. E.; AGOSTINETTO, D.; GALON, L.; MORAES, P. V. D.; PINTO, J. J. O.; NEVES, R. Métodos de manejo de Cyperus esculentus na lavoura de arroz irrigado. Planta Daninha, v.27, n.1, p.165-174, 2009. https://doi.org/10.1590/S0100-

83582009000100021

RESENDE, G. M.; BRAGA, M. B. Produtividade de cultivares e populações de cenoura em sistema orgânico de cultivo. Horticultura Brasileira, v.32, n.1, p.102-106, 2014.

https://doi.org/10.1590/S0102$\underline{05362014000100017}$

RIBEIRO, V. M.; SHEREN, M. A.; NOBREGA, L. H. P. Efeito alelopático de tiririca (Cyperus rotundus L.) sobre o desenvolvimento de milho (Zea mays L.). Journal of Agronomic Sciences, Umuarama, v.3, n.1, p.308-316, 2014.

RODRIGUES, D. H. S.; ABES, S. S.; FERNANDES, G. H.; SANTOS, J. P. G.; COSTA, A. C.; BARDIVIESSO, D. M. Efeito do extrato de tiririca no enraizamento de estacas de limão-Tahiti. Revista Verde de Agroecologia e Desenvolvimento Sustentável, v.15, n.2, p.215-220,2020. https://editoraverde.org/gvaa.com.br/revista/ind ex.php/RVADS/article/view/7370/7799.

https://doi.org/10.18378/rvads.v15i2.7370

SCHEREN, M. A.; RIBEIRO, V. M.; NOBREGA, L. H. P. Efeito alelopático de Cyperus rotundus L. no desenvolvimento de plântulas de milho (Zea mays L.). Revista Varia Scientia Agrária, v. 4, n. 1, p. 105-116, $2014.2 \quad$ http://erevista.unioeste.br/index.php/variascientiaagraria Larticle/view/9209/9052

SOUZA, D. O.; AGUSTINI, R.; ROMERO, G. S.; RUEDA, P. E. S.; GALATI, V. C. Allelopathic potential aqueous extract of tubers of tiririca in the growth and development of lettuce. Scientific Electronic Archives, v.13, n.4, p.65-70, 2020. https://doi.org/10.36560/1342020884

SOUZA, M. F.; PEREIRA, E. O.; MARTINS, M. Q.; COELHO, R. I.; PEREIRA JUNIOR, O. S. Efeito do extrato de Cyperus rotundus na rizogênese. Revista de Ciências Agrárias, v.35, n.1, p.157-162, 2012.

https://scielo.pt/pdf/rca/v35n1/v35n1a15.pdf
TEÓFILO, T. M. S.; FREITAS, F. C. L.; NEGREIROS, M. Z.; LOPES, W. A. R.; VIEIRA, S. S. V. S. Crescimento de cultivares de cenoura nas condições de Mossoró-RN. Caatinga, v.22, n.1, p.168-174, 2009.

https://periodicos.ufersa.edu.br/index.php/caatin $\mathrm{ga} /$ article/view/402/523

ZANELLA, B. E.; MOREIRA, G. C. Adubação nitrogenada na cultura da cenoura. Cultivando Saber, v.6, n.2, p.47-55, 2013. 